\title{
Endobronchial Metastasis of a Primary Transitional-Cell and Signet-Ring Cell Carcinoma of the Urinary Bladder
}

\author{
Nedim Çekmen MD, Sonay Açiksöz MD, Hacer Serdaroğlu MD, \\ Özcan Erdemli MD, and Tansel Inan MD
}

\begin{abstract}
Endobronchial metastasis is generally a late finding of primary tumor or may be determined before the diagnosis of primary tumor. We present a rare case of primary transitional and signet-ring cell carcinoma of the urinary bladder that occurred with malignant pleural effusion and endobronchial metastasis. A 71-year-old man complained of dyspnea and hematuria. He was admitted to the intensive care unit (ICU) with a prediagnosis of acute respiratory failure. He had decreased respiratory sounds and fine rales bilaterally at the lung bases. Respiratory failure worsened, and he was placed on mechanical ventilation. Radiograph and computed tomogram revealed bilateral effusion and metastatic nodules in the lung parenchyma. Subsequent abdominal computed tomogram revealed a mass in the urinary bladder, and transurethral biopsy indicated transitional epithelial carcinoma (modified Bergvist grade IIIB, and World Health Organization/International Society of Urological Pathology higher-grade urothelial papillary carcinoma) and signet-ring cell carcinoma, with lymphovascular invasion, consistent with the pathology findings. Our treatment plan was radical cysto-prostatectomy, followed by chemotherapy and radiotherapy, but because of his very poor medical status, the operation was not performed. On the 5th ICU day he died from severe respiratory failure, despite intensive supportive therapy. This case highlights the need to rule out malignancies in other organs in patients admitted with severe respiratory symptoms. Key words: dyspnea; endobronchial metastasis; signet-ring cell bladder carsinoma. [Respir Care 2011;56(7):10331036. (C) 2011 Daedalus Enterprises]
\end{abstract}

\section{Introduction}

It is reported that $95 \%$ of primary carcinomas of the urinary bladder are transitional-cell carcinomas. Bladder adenocarcinomas account for $0.5-2 \%$ of all malignant tumors of the bladder. The mucinous and primary signetring cell carcinoma subtypes are rare and constitute $20 \%$ of these tumors. ${ }^{1-3}$ More than $90 \%$ of primary signet-ring cell carcinomas originate in the stomach, breast, or colon.

Drs Çekmen, Açiksöz, Serdaroğlu, and Erdemli are affiliated with the Department of Anesthesiology and Intensive Care; and Dr Inan is affiliated with the Department of Urology, Guven Hospital, Ankara, Turkey.

The authors have disclosed no conflicts of interest.

Correspondence: Nedim Çekmen MD, Department of Anesthesiology and Intensive Care, Guven Hospital, İlko Sitesi 2796.sok No:12 Çayyolu Mah, Yenimahalle, Ankara, Turkey. E-mail: nedimcekmen@yahoo.com.

DOI: $10.4187 /$ respcare.00949
Primary signet-ring cell carcinoma growth causes late symptoms, and late diagnosis results in poor prognosis, compared to other urothelial tumors. Thus, metastases from other sites must be ruled out before a primary signet-ring cell carcinoma of the bladder is diagnosed. ${ }^{4-6}$ Endobronchial metastasis generally appears as a late finding of a primary tumor, and it is rare to identify an endobronchial metastasis before diagnosing the primary tumor. ${ }^{1-3}$ The first report related to endobronchial metastatic disease was published in $1890 .^{3}$ Endobronchial metastasis is a rare condition in extra-pulmonary malignant solid tumors, and its reported incidence is $2-5 \%$ in autopsy series. It has been observed in many studies that the most frequent primary tumors related to endobronchial metastasis are head, neck, lung, prostate, breast, colon, and renal adenocarcinoma. ${ }^{2-5}$ We present a rare case of primary transitional and signet-ring cell carcinoma of the urinary bladder that occurred with malignant pleural effusion, and endobronchial metastasis is discussed. 


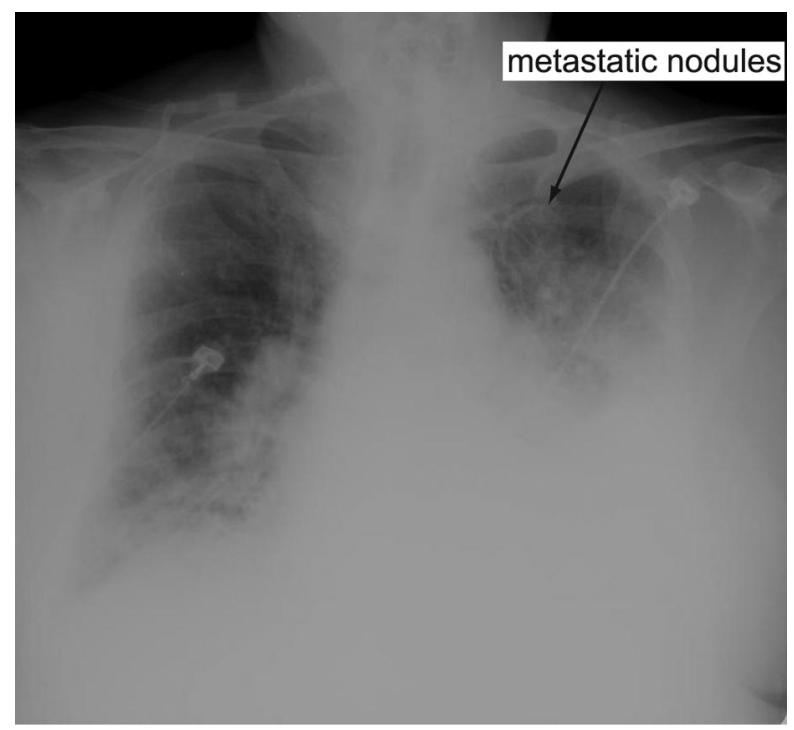

Fig. 1. Radiograph shows diffuse bilateral pleural effusion and multiple metastatic nodules, the largest of which is in the apical left lung.

\section{Case Report}

A 71-year-old man presented to the emergency department with a 1-week history of difficulty breathing and hematuria. He had no history of systemic problems, but he had a smoking habit of one pack per day. Physical examination found dyspnea, respiratory rate 34 breaths $/ \mathrm{min}$, temperature $35.6 \mathrm{C}^{\circ}$, blood pressure $160 / 90 \mathrm{~mm} \mathrm{Hg}$, heart rate 135 beats/min, and $\mathrm{S}_{\mathrm{pO}_{2}} 67 \%$. He was admitted to the intensive care unit. He was confused and his Glasgow coma score was 9. Lung auscultation revealed decreased respiratory sounds bilaterally, with crepitating rales. Radiograph revealed diffuse bilateral pleural effusion and multiple metastatic nodules (the largest of which was in the apical left lung) (Fig. 1). His Acute Physiology and Chronic Health Evaluation II score was 28, and his Multiple Organ Dysfunction Score was 6. Arterial blood gas analysis showed metabolic acidosis due to hypoxemia: bicarbonate $17.2 \mathrm{mmol} / \mathrm{L}, \mathrm{pH} 7.13, \mathrm{P}_{\mathrm{aCO}_{2}} 35 \mathrm{~mm} \mathrm{Hg}$, and $\mathrm{P}_{\mathrm{aO}_{2}} 37 \mathrm{~mm} \mathrm{Hg}$ while on nasal oxygen at $6 \mathrm{~L} / \mathrm{min}$. He was intubated and mechanically ventilated.

Laboratory analyses showed leukocyte $13,400 / \mu \mathrm{L}$, hemoglobin $13.8 \mathrm{~g} / \mathrm{dL}$, thrombocyte $279,000 / \mu \mathrm{L}$, albumin $2.4 \mathrm{mg} / \mathrm{dL}, \mathrm{Na}^{+} 119 \mathrm{mEq} / \mathrm{L}, \mathrm{K}^{+} 4 \mathrm{mEq} / \mathrm{L}$, erythrocyte sedimentation rate $42 \mathrm{~mm} / \mathrm{h}$, C-reactive protein $165 \mathrm{mg} / \mathrm{L}$, and creatinine $1.3 \mathrm{mg} / \mathrm{dL}$. He had dilution hyponatremia due to plural effusion. Electrocardiogram and echocardiography revealed normal ventricular function and no signs of ischemia. Computed tomogram (CT) showed bilateral plural effusion plus multiple subpleural and parenchymal metastatic nodules at the left apex, the largest of which was $23 \times 19 \mathrm{~mm}$ (Fig. 2). Sputum-smear acid-

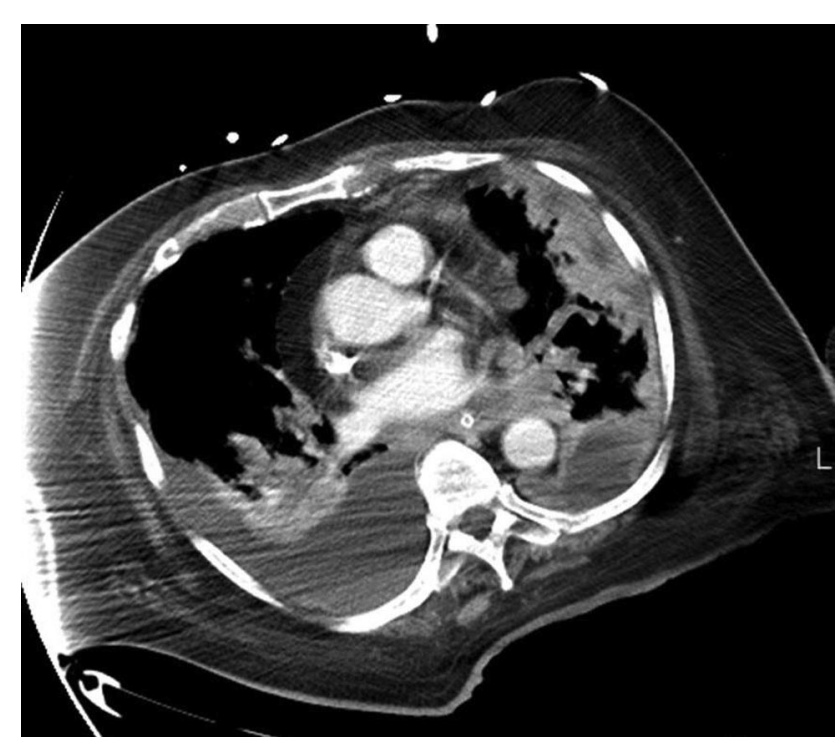

Fig. 2. Computed tomogram shows bilateral plural effusion and multiple subpleural and parenchymal metastatic nodules at the left apex, the largest of which is $23 \times 19 \mathrm{~mm}$.

resistant bacillus test for tuberculosis was negative. To test for autoimmune or collagen tissue disorders that could cause a similar appearance in the lung, we conducted antinuclear antibody, anti-double-stranded deoxyribonucleic acid, perinuclear anti-neutrophil cytoplasmic antibody, and diffuse cytoplasmic antineutrophil cytoplasmic antibody tests, all of which were negative as well. Sputum examination and culture for fungal hyphae and other pathogens that may cause a similar appearance were also negative. Biochemical analysis of $1,500 \mathrm{~mL}$ of fluid collected via thoracentesis found that protein, albumin, and $\mathrm{Na}^{+}$were low, which indicates exudative pleural effusion, but the fluid contained atypical cells determined on cytology specimens. Dilutional hypoalbuminemia $(2.6 \mathrm{~g} / \mathrm{dL})$ and hyponatremia $(121 \mathrm{mEq} / \mathrm{L})$ were detected, probably due to pleural effusion. Histopathology of forceps biopsy material obtained via fiberoptic bronchoscopy found epithelial tumor cells and pleomorphic primary signet-ring cells containing intracytoplasmic mucin, and these cells formed patchy small islets inside the stroma of fatty tissue and could be distinguished from a papillary configuration. Urine microscopy showed $7-8$ leukocytes, abundant erythrocytes, and 3-4 epithelium on urinalysis. We suspected an extrapulmonary malignant tumor had caused an endobronchial metastasis, and abdominopelvic CT found a solid mass with distribution inside and outside the urinary bladder. Because he had no histological diagnosis, we conducted cystoscopy and bimanual examination. The bladder was mobile on bimanual examination. Cystoscopy under general anesthesia found a solid mass which we forceps biopsied, and histology found atypical cells with pleomorphism and hyperchromatic nuclei in cells of transitional 
epithelial origin, frequent mitosis, and signet-ring cell appearance. Our diagnosis was bladder transitional epithelial carcinoma (modified Bergvist grade III B, and World Health Organization/International Society of Urological Pathology higher-grade urothelial papillary carcinoma) and primary signet-ring cell carcinoma with lymphovascular invasion, consistent with the pathology findings. We planned radical cystoprostatectomy, chemotherapy, and radiotherapy, but the patient could not be operated on or started on anti-tumor treatment, because his vital signs were not stable and his medical status was bad. He died from irreversible respiratory failure 5 days following the diagnosis.

\section{Discussion}

Signet-ring cell carcinoma of the urinary bladder can be primary, arising from the bladder wall or urachus remnants; or metastatic, from a tumor in the stomach, colon, or breast. Primary signet-ring cell carcinoma of the urinary bladder was first described in 1955 . Less than 100 cases have been reported. It develops at the base of metaplasia or due to prolonged local irritation in adenocarcinomas such as squamous-cell cancers. Most of these primary adenocarcinomas originate from the base of the bladder, and the rest occur together with the remnants of urachus residues localized at the dome. Primary signet-ring cell carcinoma has the worst course among the primary adenocarcinomas. Generally, this type of neoplasm occurs in middle age, and the clinical presentation does not differ from the most frequent transitional-cell carcinomas.

The primary symptom of bladder cancer is hematuria, usually without pain. The hematuria can be macroscopically visible or microscopic. Bladder cancer must be ruled out in any patient who develops gross, painless hematuria. Diagnosing bladder cancer requires urological tests and imaging. Risk factor include cigarette smoking, heavy consumption of coffee, male sex, chronic lower-urinary-tract infection, familial history of bladder cancer, occupational history (ever-employed in the printing, plastics, synthetics industries), artificial sweeteners, ionizing radiation, and cyclophosphamide use. If bladder cancer is suspected, cystoscopy with biopsy should be performed. Usually the prognosis is poor at the time of diagnosis, because it is often found in an advanced phase. It is essential to distinguish this carcinoma from metastases, because different therapies may be needed. ${ }^{2,5}$ Urine cytology is mostly positive due to desquamated tumor cells. Microscopically, it has the same characteristics as primary signet-ring cell carcinoma of the lung. Metastases are generally identified at an advanced stage because of their aggressiveness, and late diagnosis is associated with bad prognosis. The tumor makes early local metastases, and distant metastases originate generally from the lymph nodes, bone, ovaries, pleura, pericardium, or meninges, but rarely from the lungs. ${ }^{5-7}$
Pulmonary metastasis is seen in $20 \%$ of transitional-cell carcinoma of the bladder. Forty-six percent of these metastases are reported as multiple nodules, $25 \%$ as solitary nodules, $17 \%$ as infiltrates, $7 \%$ as pulmonary edema, $3 \%$ as Pancoast tumor. ${ }^{2,3}$ The occurence of both transitionalcell and primary signet-ring cell carcinoma together, recognized via respiratory symptoms, and consistent with endobronchial metastasis, is very rare in the literature, so its incidence is not clear. ${ }^{3-6}$ The pulmonary involvement may be parenchymal or lymph node metastasis. Metastatic involvement of the main bronchi cannot be discriminated from bronchogenic carcinoma with central localization by clinical and radiological findings. ${ }^{6}$ The leading symptoms are cough, loss of appetite, weight loss, chest pain, and hemoptysis in most cases. Dyspnea is rare. Asymptomatic cases have been reported. Diagnostic tests include radiograph, CT, magnetic resonance imaging, bronchoscopic needle biopsy with CT guidance, and bone scintigraphy. ${ }^{3,5}$

Romics et $\mathrm{al}^{8}$ reported that they diagnosed primary signet-ring cell carcinoma of the left bladder wall on biopsy via transurethral cystoscopy on a 45-year-old female patient who presented with gross hematuria. Egevad et al ${ }^{9}$ reported that they made the diagnosis of primary signetring cell carcinoma of the bladder the biopsy via transurethral cystoscopy on 2 male patients, ages 53 and 51 years. Similarly, Fujita et al ${ }^{10}$ reported that they diagnosed primary signet-ring cell carcinoma of the bladder on biopsy via transurethral cystoscopy on a 60 -year-old male patient who presented with gross hematuria. Yamashito et $\mathrm{al}^{11}$ reported that they diagnosed primary signet-ring cell carcinoma of primary origin on transurethral cystoscopy biopsy of the urinary bladder, abdominal CT, and bone scintigraphy in a 71-year-old male patient who presented with dyspnea, general fatigue, and impaired renal function. It is interesting that our patient presented with respiratory symptoms and had endobronchial metastasis from the urinary bladder.

With solid-organ tumors the lungs are generally investigated as a common locus for metastasis. ${ }^{6}$ The most frequent radiological findings in endobronchial metastasis of extra-pulmonary carcinomas are single or multiple nodules or atelectasis. ${ }^{5,6}$ Our patient had diffuse bilateral pleural effusion, metastatic nodules, and atelectasis on radiograph and CT.

Bronchoscopy is the most valuable diagnostic method for endobronchial metastases, and is very useful for differentiating conditions that radiologically mimick metastasis, and for therapy selection. Bronchoscopy should include brushings, washings of the respiratory tissues for cell analysis, and biopsy. If the bronchoscopy findings are unrevealing, or "negative," a needle biopsy may be performed. ${ }^{12}$ Díaz et al ${ }^{12}$ found that the diagnosis rate with broncoscopy was $72.6 \%$ in 113 cases. In our patient the 


\section{Endobronchial Metastasis of a Bladder Carcinoma}

diagnosis was obtained directly from forceps biopsy of the endobronchial lesion.

Determining whether the lesion is primary, urachal, or metastatic in origin is very important in the staging, selection of treatment, and disease course. ${ }^{5,6}$ The response to chemotherapy or radiotherapy is limited. The preferred approach for localized tumors is radical cystectomy and systemic chemotherapy, but surgery is controversial in patients who have complete response with chemotherapy. ${ }^{5-7}$ For our patient with transitional-cell and primary signetring cell carcinoma we planned radical cystoprostatectomy, extended lymph node dissection, and adjuvant chemotherapy and radiotherapy, but his condition contraindicated those treatments.

Transitional-cell and primary signet-ring cell carcinoma are usually diagnosed at an advanced stage and have a poor prognosis. Although the overall prognosis of this condition is poor, it is still dependent on the tumor stage at diagnosis. ${ }^{6}$ The time between diagnosis of primary tumor of the bladder and the appearance of endobronchial metastasis ranges between average 9 months and 5 years. Even though symptomatic improvement is provided with local treatment, survival after recognition of an endobronchial metastasis is short. The survival rate has been reported as 1-2 years in most cases. ${ }^{6,7}$

Our patient was admitted with gradually increasing respiratory symptoms over the previous 10 days, and because respiratory symptoms and hypoxemia were evident at admission, we preliminarily thought his condition was of pulmonary origin. This case highlights the need to consider nonpulmonary malignancies and other possible conditions in other organs in patients admitted for severe respiratory symptoms.

\section{REFERENCES}

1. Messing EM. Urothelial tumors of the bladder; Campbell-Walsh urology, 9th edition. Philadeelphia: WB Saunders; 2007:2407-2446.

2. Abol-Enein H, Kava BR, Carmack AJ. Nonurothelial cancer of the bladder. Urology 2007;69(1):93-104.

3. Trias I, Algaba F, Condom E, Español I, Seguí J, Orsola I, et al. Small cell carcinoma of the urinary bladder: presentation of 23 cases and review of 134 published cases. Eur Urol 2001;39(1):85-90.

4. Andreeva lulu, Zavalishina LE, Maïnovskaia OA, Bateva MV, Frank GA. Signet-ring cell carcinoma of the bladder. Arkh Patol 2007; 69(6):32-34.

5. Ploeg M, Aben KK, Hulsbergen-van de Kaa CA, Schoenberg MP, Witjes JA, Kiemeney LA. Clinical epidemiology of nonurothelial bladder cancer: analysis of the Netherlands Cancer Registry. J Urol 2010;183(3):915-920.

6. Katsimbri PP, Bamias AT, Froudarakis ME, Peponis IA, Constantopoulos SH, Pavlidis NA. Endobronchial metastases secondary to solid tumors: report of eight cases and review of the literature. Lung Cancer 2000;28(2):163-170

7. Siefker-Radtke AO, Gee J, Shen Y, Wen S, Daliani D, Millikan $\mathrm{RE}$, et al. Multimodality management of urachal carcinoma. The MD Anderson Cancer Center Experience. J Urol 2003;169(4):12951298.

8. Romics I, Székely E, Szendroi A. Signet-ring cell carcinoma arising from the urinary bladder. Can J Urol 2008;15(5):4266-4268.

9. Egevad L, Håkansson U, Grabe M, Ehrnstrom R. Urachal signet-cell adenocarcinoma. Scand J Urol Nephrol 2009;43(1):88-91.

10. Fujita M, Otoshi T, Kobayashi K, Fukumoto R, Imamura R, Takada $\mathrm{S}$, et al. Primary signet-ring cell carcinoma of the urinary bladder: a case report. Hinyokika Kiyo 2009;55(9):579-582. Article in Japanese.

11. Yamashita R, Mashima E, Ogishima T, Wakumoto Y, Sakamoto Y, Fujime M. Primary signet ring cell carcinoma of the bladder: a case report. Hinyokika Kiyo 2005;51(2):117-119. Article in Japanese.

12. Díaz G, Jiménez D, Domínguez-Reboiras S, Carrillo F, Pérez-Rodríguez E. Yield of bronchoscopy in the diagnosis of neoplasm metastatic to lung. Respir Med 2003;97(1):27-29. 